\title{
Synthesis of new polyisocyanates
}

Guy Koeckelberghs, Marcel Van Beylen, Celest Samyn*

Laboratory of Macromolecular and Physical Organic Chemistry, University of Leuven, Celestijnenlaan 200F, B-3001 Heverlee, Belgium.

Keywords : Polyisocyanates, synthesis

* To whom correspondence should be addressed

Tel: + 32(0)13/327438 Fax: +32(0)16/327990

e-mail: celest.samyn@chem.kuleuven.ac.be 


\begin{abstract}
Novel isocyanates functionalised with either a halogen or methyl ester substituent have been synthesised, then polymerised to form the corresponding functionalised polyisocyanates using ${ }^{-} \mathrm{CN}$ as the initiator. Transesterification of the polymer carrying ester groups using alcohol chromophores, yielded polyisocyanates loaded with up to $30 \%$ of segments of chromophore. Attempts to similarly derivatise the chloride substituted polymer lead to decomposition.
\end{abstract}




\section{Introduction}

Polyisocyanates ${ }^{1-7}$ are a relatively new class of polymers. One of the most interesting properties of these polymers is their macrostructure. Poly(alkyl as well as aryl isocyanates) are known to be stiff rod-like macromolecules in both solution and solid state. This helical conformation can give rise to large C.D.-effects and very large optical rotations. Polyisocyanates are also of great importance in the study of worm-like states ${ }^{8-}$ 10

Another interesting property of these polymers is the extreme sensitivity for slight chiral influences ${ }^{11}$. Green et al. discovered that the optical activity in polyisocyanates with random sequence of $(\mathrm{R})$ and $(\mathrm{S})$ pendant groups sharply responds to the enantiomeric excess (majority rule) ${ }^{12}$. Likewise, in polyisocyanates with random sequence of chiral (sergeants) and achiral (soldiers) units, the optical activity responds very sharply to the concentration of chiral units (sergeants-and-soldiers effect) ${ }^{13}$.

Most of the investigated poly(alkyl isocyanates) were unfunctionalised. This greatly limits the possibility of these interesting polymers to be used in the fields of nonlinear optics, asymmetric catalysis, etc. Therefore, we synthesised halogen and methyl ester functionalised polyisocyanates. By means of a transesterification reaction, we could successfully introduce chromophores into the methyl ester polymers. 


\title{
Experimental part
}

\section{Materials and instrumentation}

\begin{abstract}
All reagents were purchased from Aldrich Chemical Co. and Acros Organics. Reagent grade solvents were dried when necessary and purified by distillation.
\end{abstract}

The glass transition temperatures were measured with a DCS-7 apparatus from Perkin Elmer with a heating rate of $10^{\circ} \mathrm{C} / \mathrm{min}$.

Gel permeation chromatography (GPC) measurements were done with a Waters apparatus with a tunable absorbancy detector and a differential refractometer, in tetrahydrofuran (THF) as eluent towards polystyrene standards.

\footnotetext{
${ }^{1} \mathrm{H}$ nuclear magnetic resonance (NMR) measurements were done with a Bruker $250 \mathrm{MHz}$ apparatus.
}

Synthesis of (R)-(+)-2,6-dimethylhepthyl isocyanate (5)

$(R)-(+)$-citronellic acid (2): Compound 2 was prepared from (R)-(+)-pulegone as described in reference 14 . Yield : 40\%; b.p.: $96^{\circ} \mathrm{C} / 0.2 \mathrm{~mm} \mathrm{Hg}$. 
$(R)-(+)$-dihydrocitronellic acid (3): Compound 2 was hydrogenated over 10\% Pd-C in ethanol as described in reference 15. Yield : 82\%; b.p.:76- $85^{\circ} \mathrm{C} / 0.4 \mathrm{~mm} \mathrm{Hg}$.

$(R)-(+)$-dihydrocitronelloyl chloride (4): The procedure of Zentel et al. ${ }^{16}$ was used: 15.9 $\mathrm{g}(250 \mathrm{mmol})$ of oxalyl chloride was slowly added to $100 \mathrm{mmol}$ of acid. After stirring overnight at room temperature, the excess of oxalyl chloride was evaporated and the acyl chloride was purified by vacuum distillation. Yield: $95 \%$; b.p.:98 $\mathrm{C} / 20 \mathrm{~mm} \mathrm{Hg}$.

$(R)-(+)-2,6$-dimethylhepthyl isocyanate (5): The isocyanate was synthesised under the same conditions as in reference 16 : To $50 \mathrm{mmol}$ of acyl chloride in $10 \mathrm{ml}$ of dry toluene, $7.5 \mathrm{~g}(65 \mathrm{mmol})$ of trimethylsilyl azide was added. The mixture was heated to $75^{\circ} \mathrm{C}$ for 20 minutes under argon atmosphere and then heated to reflux for 30 minutes. After evaporation of the volatile components in the reaction mixture, the product was purified by fractional distillation under reduced pressure. Yield : 93\%; b.p.:95 ${ }^{\circ} \mathrm{C} / 20 \mathrm{~mm} \mathrm{Hg}$.

Synthesis of 3-chloropropyl isocyanate(6)

3-chloropropyl isocyanate(6): A modified procedure as described for the synthesis of 5 was used: Since toluene forms an azeotropic mixture with the isocyanate, the reaction is carried out in the absence of solvent. Yield: $82 \%$; b.p.: $78.5^{\circ} \mathrm{C} / 15 \mathrm{~mm} \mathrm{Hg} ;{ }^{1} \mathrm{H}-$ $\operatorname{NMR}\left(250 \mathrm{MHz}, \mathrm{CDCl}_{3}\right): \delta 3.71(\mathrm{t}, 2 \mathrm{H}), 3.60(\mathrm{t}, 2 \mathrm{H}), 2.11(\mathrm{qu}, 2 \mathrm{H})$.

Synthesis of 2-iodoethyl isocyanate(8) 
3-iodopropanoyl chloride(7): The same procedure as for $\mathbf{4}$ was followed. Yield: 83\%: b.p.: $74^{\circ} \mathrm{C} / 15 \mathrm{~mm} \mathrm{Hg} ;{ }^{1} \mathrm{H}-\mathrm{NMR}\left(250 \mathrm{MHz}, \mathrm{CDCl}_{3}\right): \delta 3.53(\mathrm{t}, 2 \mathrm{H}), 3.34(\mathrm{t}, 2 \mathrm{H})$.

2-iodoethyl isocyanate(8): The same procedure as for $\mathbf{5}$ was followed. Yield: 76\%; b.p.: $68^{\circ} \mathrm{C} / 15 \mathrm{~mm} \mathrm{Hg} ;{ }^{1} \mathrm{H}-\mathrm{NMR}\left(250 \mathrm{MHz}, \mathrm{CDCl}_{3}\right): \delta 3.68(\mathrm{t}, 2 \mathrm{H}), 3.32(\mathrm{t}, 2 \mathrm{H})$.

Synthesis of methyl 3-isocyanatopropanoate(11)

monomethylsuccinate $(9): 60.0 \mathrm{~g}(0.60 \mathrm{~mol})$ of succinic anhydride was dissolved in 120 $\mathrm{ml}$ of methanol and the solution was refluxed for $5 \mathrm{~h}$. After evaporation of the excess of methanol, the crude product was recrystallised from toluene. Yield: 75.3g (95\%); $\mathrm{T}_{\mathrm{m}}=59.5^{\circ} \mathrm{C} ;{ }^{1} \mathrm{H}-\mathrm{NMR}\left(250 \mathrm{MHz}, \mathrm{CDCl}_{3}\right): \delta 3.72(\mathrm{~s}, 3 \mathrm{H}), 3.22(\mathrm{t}, 2 \mathrm{H}), 2.68(\mathrm{t}, 2 \mathrm{H})$.

monomethylsuccinoyl chloride(10): The same procedure as for $\mathbf{4}$ was followed. Yield: $79 \%$; b.p.: $90^{\circ} \mathrm{C} / 15 \mathrm{~mm} \mathrm{Hg} ;{ }^{1} \mathrm{H}-\mathrm{NMR}\left(250 \mathrm{MHz}, \mathrm{CDCl}_{3}\right): \delta 3.72(\mathrm{~s}, 3 \mathrm{H}), 3.02(\mathrm{t}, 2 \mathrm{H})$, $2.62(\mathrm{t}, 2 \mathrm{H})$.

methyl 3-isocyanatopropanoate(11): The same procedure as for $\mathbf{5}$ was followed. Yield: 80\%; b.p.: $84.5^{\circ} \mathrm{C} / 15 \mathrm{~mm} \mathrm{Hg} ;{ }^{1} \mathrm{H}-\mathrm{NMR}\left(250 \mathrm{MHz}, \mathrm{CDCl}_{3}\right): \delta 3.73(\mathrm{~s}, 3 \mathrm{H}), 3.60(\mathrm{t}, 2 \mathrm{H})$, $2.63(\mathrm{t}, 2 \mathrm{H})$.

Synthesis of 2-[4-((4-cyanophenyl)azo)phenyloxy]ethanol(13) 
4-[(4-nitrophenyl)azo]phenol(12): A stirred suspension of $23.6 \mathrm{~g}(0.20 \mathrm{~mol})$ of 4cyanoaniline in a mixture of $50 \mathrm{ml}$ of concentrated hydrochloric acid and $140 \mathrm{ml}$ of water was treated dropwise with $15 \mathrm{~g}(0.22 \mathrm{~mol})$ of sodium nitrite in $30 \mathrm{ml}$ of water at $0^{\circ} \mathrm{C}$. After complete formation of the diazonium salt, $27.3 \mathrm{~g}(0.29 \mathrm{~mol})$ of phenol in $30 \mathrm{ml}$ of glacial acetic acid was slowly added, keeping the temperature below $0^{\circ} \mathrm{C}$. Once the addition was completed, the reaction mixture was stirred for 30 minutes and a solution of $30 \mathrm{~g}$ of sodium acetate in water was added. After another hour of stirring, the mixture was neutralised with a sodium hydroxide solution and allowed the reach room temperature. The precipitate was filtered off, washed two times with acetic acid and recrystallised from ethanol-water. Yield: $40.6 \mathrm{~g}(91 \%) ; \mathrm{T}_{\mathrm{m}}: 191^{\circ} \mathrm{C} ;{ }^{1} \mathrm{H}-\mathrm{NMR}(250 \mathrm{MHz}$, DMSO-d6): $\delta$ 9.20(s, 1H), 8.08(d, 2H), 7.92(m, 4H), 7.06(d, 2H).

2-[4-((4-cyanophenyl)azo)phenyloxy]ethanol(13): To a suspension of $1.92 \mathrm{~g}(0.08 \mathrm{~mol})$ of sodium hydride in $30 \mathrm{ml}$ of DMF, $15.6 \mathrm{~g} \mathrm{(0.07} \mathrm{mol)} \mathrm{of} \mathrm{12,} \mathrm{dissolved} \mathrm{in} 130 \mathrm{ml}$ of DMF, was added dropwise. $0.5 \mathrm{~g}$ of potassium iodide and $5.67 \mathrm{ml}(0.08 \mathrm{~mol})$ of 2bromoethanol were added and the mixture was stirred for $24 \mathrm{~h}$ at $100^{\circ} \mathrm{C}$ under argon atmosphere. After cooling, chloroform was added and the organic layer was washed twice with a saturated sodium bicarbonate solution, then with brine and dried over magnesium sulfate. After filtration, the solvents were removed and the crude reaction product was recrystallised from chloroform. Yield:16.3 g $(87 \%) ; \mathrm{T}_{\mathrm{m}}: 185^{\circ} \mathrm{C} ;{ }^{1} \mathrm{H}-$ NMR(250MHz, DMSO-d6): 8 8.08(d, 2H), 7.92(m, 4H), 7.18(d, 2H), 4.98(t, 1H), 4.11(t, 2H), 3.78(m, 2H). 
Synthesis of [2-((S)-(+)-(2-methyl)butoxy)-5-((4-nitrophenyl)azo)phenyl]methanol(15)

[(2-hydroxy)-5-((4-nitrophenyl)azo)phenyl]methanol (14): The same procedure, as described for (12), was used, starting from 4-nitroaniline and 2-hydroxyphenylmethanol. Yield: $75 \%$; $\mathrm{T}_{\mathrm{m}}: 172{ }^{\circ} \mathrm{C} ;{ }^{1} \mathrm{H}-\mathrm{NMR}(250 \mathrm{MHz}, \mathrm{DMSO}-\mathrm{d} 6): \delta 10.42(\mathrm{~s}, 1 \mathrm{H}), 8.40(\mathrm{~d}, 2 \mathrm{H})$, 7.98(m, 3H), 7.72(d×d, 1H), 6.91(d, 2H), 4.53(s, 2H).

[2-((S)-(+)-(2-methyl)butoxy)-5-((4-nitrophenyl)azo)phenyl]methanol(15): The same procedure as for 13 was followed, using 14 and (S)-(+)-1-bromo-2-methylbutane as starting materials and in this case, no excess of sodium hydride was used. The crude reaction product was purified by column chromatography (silicagel; eluent: $\mathrm{CHCl}_{3}$ / $\left.\mathrm{CH}_{3} \mathrm{CN} 50: 50 \mathrm{v} / \mathrm{v}\right)$ and isolated as an oil. Yield: $60 \% ;{ }^{1} \mathrm{H}-\mathrm{NMR}(250 \mathrm{MHz}, \mathrm{DMSO}-\mathrm{d} 6): \delta$ 10.21(s,1H), 8.40(d, 2H), 8.06(m, 3H), 7.90(d×d, 1H), 6.91(d, 2H), 5.30(t,1H), 4.54(s, $2 \mathrm{H}), 3.97(\mathrm{~m}, 2 \mathrm{H}), 1.88(\mathrm{~m}, 1 \mathrm{H}), 1.54(\mathrm{~m}, 1 \mathrm{H}), 1.30(\mathrm{~m}, 1 \mathrm{H}), 1.09(\mathrm{~d}, 3 \mathrm{H}), 0.98(\mathrm{t}, 3 \mathrm{H}) ;[\alpha]_{\mathrm{D}}^{20}=$ $+298 \mathrm{deg} \cdot \mathrm{dm}^{-1} \cdot \mathrm{g}^{-1} \cdot \mathrm{ml} \cdot\left(\mathrm{c}=5 \cdot 0 \cdot 10^{-2}\right.$, in $\left.\mathrm{CHCl}_{3}\right)$.

\section{Polymer synthesis}

All monomers were distilled over $\mathrm{CaH}_{2}$ just before use. $\mathrm{NaCN}$ was heated under vacuum for 3 days and DMF was distilled three times onto molecular sieve. The monomer (mixtures) and DMF (0.8 ml solvent per mmol isocyanate) were brought under argon in a polymerisation tube. The tube was equipped with a magnetic stirrer and sealed with a 
septum. The temperature was fixed at $-60^{\circ} \mathrm{C}$ under a constant argon flow and the initiator, a solution of $\mathrm{NaCN}$ in $\mathrm{DMF}(0.2 \mathrm{M})$, was injected $(0.5 \mathrm{~mol} \%)$. After a few seconds, the polymer precipitated (polymers 1-3) or the solution became glassy (polymers 4 and 5). Then, after 30 minutes, $0.5 \mathrm{ml}$ of methanol was added to stop the polymerisation and the polymer was further precipitated in methanol. For purification, the polymer was dissolved in THF and reprecipitated in methanol.

\section{Functionalisation of polymer 4 and 5}

$0.5 \mathrm{~g}$ of polymer was dissolved in $25 \mathrm{ml}$ of 1,2-dichloroethane and purged with argon. To this solution, $0.5 \mathrm{~g}$ of p-toluenesulfonic acid and $35 \mathrm{mmol}$ of chromophore alcohol were added and the mixture was stirred under argon at $50^{\circ} \mathrm{C}$ for 48 hours. After cooling, the polymer was precipitated in $100 \mathrm{ml}$ of methanol. For purification, the polymer was dissolved five times in THF and reprecipitated in methanol. 


\section{Results and discussion}

To design polyisocyanates useful for specific domains, such as nonlineair optics, one has to introduce functional groups and moieties, like chromophores, into the polymer system. However, since many of the functional groups are not compatible with the anionic nature of the polymerisation or are not stable under the quite harsh (acidic) conditions under which the monomers are prepared, it is obvious that the number of functionalised polyisocyanates remains limited.

A solution to this problem is the synthesis of polyisocyanates containing a functional group, by which the polymer is functionalised afterwards with the desired molecules (chromophores). In the present study, four different isocyanates were prepared: chloroand iodo- functionalised isocyanate $\mathbf{6}$ and $\mathbf{8}$ and methyl ester isocyanate 11. Their structure is presented in figure 1.

[insert figure 1]

Also a chiral isocyanate $\mathbf{5}$ was prepared; its synthesis is given in scheme 1. Hexyl isocyanate $\mathbf{1}$ is a commercial product.

[insert scheme 1] 
Monomers $\mathbf{6}$ and $\mathbf{8}$ were synthesised in the same way, starting from their respective halogen functionalised carboxylic acid or acyl chloride. To prepare 11, the first step was the synthesis of 9 (scheme 2).

[insert scheme 2]

The carboxylic acid was then transformed into its acid chloride, followed by the reaction with trimethylsilyl azide, which, after heating (Curtius rearrangement), results in the formation of the isocyanate $\mathbf{1 1}$.

From these monomers copolymers as well as a homopolymer were synthesised. The results are listed in table 1.

[insert table 1]

As stated above, to be useful for nonlineair optics, chromophore molecules must be incorporated in the polymer system. Therefore, we tried to substitute the halogen in polymer 1-3. Because polyisocyanates degrade in basic media, we have tried to carry out the functionalisation with several nucleophiles, varying reaction temperature and time. We have used sodium 4-[(4-nitrophenyl)azo]phenolate and the less basic sodium 4-[4(dimethylaminophenyl)azo]benzoate, both at room temperature and boiling THF for 1 and 10 hours. However, the polymer degradation reaction appeared to be must faster than the desired substitution in all cases and no polymer could be isolated. This is consistent with the fact that polyisocyanates undergo fast base-catalysed degradation. 
[insert figure 2]

On the other hand, the polymer remained stable when treated in acidic medium with an excess of alcohol. So, we have prepared alcohol chromophores $\mathbf{1 3}$ and 15; the synthesis is shown in scheme 3.

[insert scheme 3]

We used compouds $\mathbf{1 3}$ and $\mathbf{1 5}$, because the functionalised polymers can be useful in the domain of nonlinear optics.

The transesterification reaction was carried out in 1,2-dichloroethane with ptoluenesulfonic acid as a catalyst. About a 10-fold excess of alcohol was used and seemed to be enough to reach a degree of functionalisation up to $30 \%$. In this way, copolymers $4 \mathrm{a}-5 \mathrm{~b}$ were obtained.

[insert figure 3]

The properties of the functionalised polyisocyanates are shown in table 2 .

[insert table 2] 
In the case of polymers $4 \mathrm{~b}$ and $5 \mathrm{~b}$, when the chiral chromophore was introduced, very high optical rotations were reached. Clearly, the optical activity must be due to the incorporation of the chromophore, since the prepolymer doesn't contain any chiral center and shows no optical activity. If the chromophores were attached to the polymer backbone without any influence of the polymer itself, the chromophores would just be diluted in the polymer matrix, giving rise to a lower optical rotation of the same sign. Since this is not the case (polymers $4 \mathrm{~b}$ and $5 \mathrm{~b}$ display a much larger optical activity of the opposite sign), we may assume that the polymer backbone and the chromophore do influence their respective macromolecular arrangement. On one hand, we can assume that the majority rule counts, which implies that the asymmetric center of the chromophore resolves the racemic mixture of right- and left-handed helices of the prepolymer into a nearly enantiomerically pure ensemble of one-handed helices. On the other hand, if the chromophore only induced the chirality of the polymer without any influence of the polymer backbone on the chromophore, the optical rotation would exclusively be due to the polyisocyanate (diluted with chromophore), giving rise to values up to a few hundred $\mathrm{deg}^{-1} \cdot \mathrm{dm}^{-1} \cdot \mathrm{g}^{-1} \cdot \mathrm{ml}$. Since the measured optical rotations are about 10 times higher than predicted, we assume that the chiral, helical conformation of the polymer forces a new, chiral and helical macromolecular arrangement of the chromophores. In that case, the optical rotation is caused by a new, much larger helix, consisting of the polyisocyanato backbone and the chromophores. 


\section{Conclusion}

New isocyanates have successfully been prepared and polymerised. Furthermore, we have optimised a way to functionalise polyisocyanates by means of a transesterification reaction. This may be a promising alternative to synthesise new polyisocyanates in the future. Finally, we have proven that the polymer can impose its macromolecular arrangement to introduced groups in the side chain. These synthetic as well as physical results can open the possibility for polyisocyanates to be used in new fields, such as nonlineair optics. 


\section{Acknowledgments}

G. K. is a doctoral fellow of the Fund for Scientific Research-Flanders Fonds voor Wetenschappelijk Onderzoek-Vlaanderen. We are grateful to Prof. M. M. Green for his advice concerning the polymerisation of isocyanates. 


\section{References}

(1) Shasshoua, V.E.;Sweeney, W; Tietz, R.F. J. Am. Chem.Soc. 1960, 82, 866

(2) Schneider, N.S.; Furusaki, S; Lenz, R.W. J. Polym. Sci. Part A 1965, 3, 933

(3) Yu, H; Bur, A.J.; Fetters, L.J. J. Chem. Phys. 1966, 44, 2568

(4) Bur, A.J.; Roberts, D.E. J. Chem. Phys. 1969, 51, 406

(5) Tsvetkov, V.N.; Ryumtsev, Y.I.; Aliyev, F.M.;Shtennikova, I.N.; Savvon, S.M. Polym. Sci. USSR, Ser. A 1974, 16, 1627

(6) Berger, M.N.; Tidswell, B.M. J. Polym. Sci., Polym. Symp. 1973, No 42, 1063

(7) Bur, A.J.; Fetters, L.J. Chem. Rev. 1976, 76, 727 and references therein.

(8) Rubingh, D.N.; Fu, H. Macromolecules 1976, 9, 681

(9) Mansfield, ML. Macromolecules 1983, 16, 1863

(10) Itou, T.; Chikiri, H; Teramoto, A.; Aharoni, S.M. Polym. J. 1988, 20, 143

(11) Green, M.M.; Peterson N.C.; Sato, T.; Teramoto, A.; Cook, R.; Lifson, S. Science 1995, 268,1860

(12) Green, M.M.; Garetz, B.A.; Munoz, B.; Chang, H.; Hoke, S.; Cooks, R.G. J. Am. Chem. Soc. 1995, 117, 4181

(13) Green, M.M.; Reidy, M.P.; Johnson, R.J.; Darling, G.; O’Leary, D.J.; Willson, J. J. Am. Chem. Soc. 1989, 111, 6452

(14) Overberger, C.G.; Weise, J.K. . J. Am. Chem. Soc. 1968, 90, 3525

(15) Mori, K . Tetrahedron 1982, 15, 2291

(16) Müller, M.; Zentel, R Makromol. Chem. 1993, 194, 101 


\section{Scheme and figure captions}

Scheme 1: synthesis of chiral isocyanate 5

Scheme 2: synthesis of compound 9

Scheme 3: synthesis of alcohol chromophores $\mathbf{1 3}$ and $\mathbf{1 5}$

Figure 1: functionalised isocyanates $\mathbf{6 , 8}, \mathbf{1 1}$

Figure 2: pathway for functionalisation of halogen functionalised polymers pol 1- pol 3

Figure 3: pathway for functionalisation of methyl ester functionalised polymers pol 4pol 5 
<smiles>CC(C)=C1CC[C@@H](C)CC1=O</smiles>
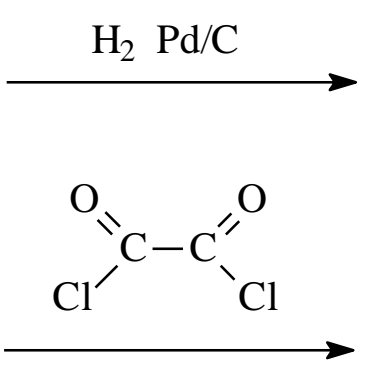

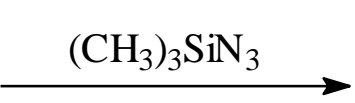

scheme 1
1) $\mathrm{HCl}$

2) ${ }^{\circ} \mathrm{OH}$<smiles>CC(C)=CCCC(C)CC(=O)O</smiles>

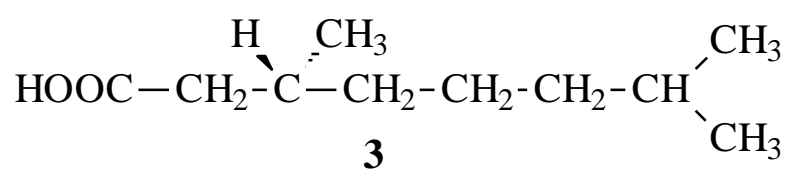<smiles>CC(C)CCCC(C)CC(=O)Cl</smiles>

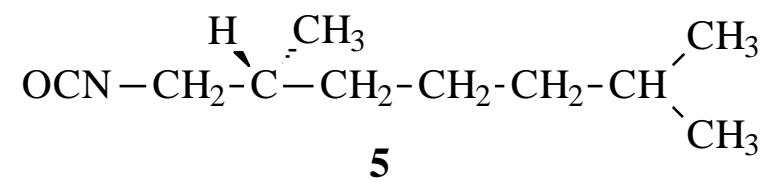



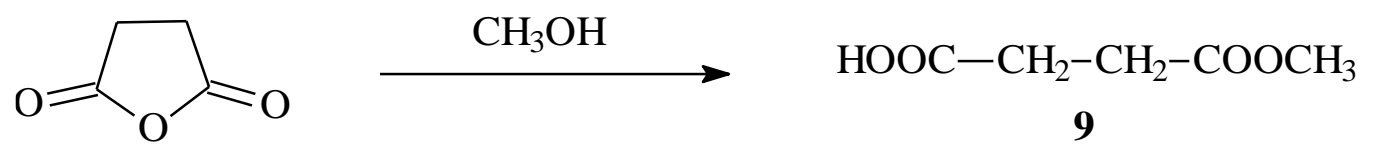

scheme 2 


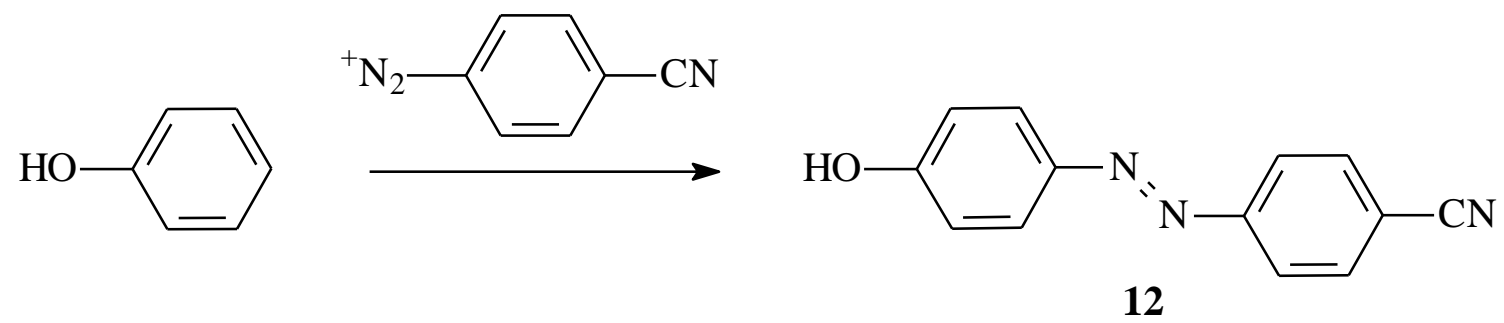

1) $\mathrm{NaH}$
2) $\mathrm{HO}-\mathrm{CH}_{2}-\mathrm{CH}_{2}-\mathrm{Br}$<smiles>N#Cc1ccc(N=Nc2ccc(OCCO)cc2)cc1</smiles><smiles>N#[N+]c1ccc([N+](=O)[O-])cc1</smiles><smiles>O=[N+]([O-])c1ccc(N=Nc2ccc(O)c(CO)c2)cc1</smiles>

1) $\mathrm{NaH}$

2) $\mathrm{H}_{3} \mathrm{C}-\mathrm{CH}_{2}-\mathrm{C}-\mathrm{CH}_{2}-\mathrm{Br}$<smiles>CCC(C)COc1ccc(N=Nc2ccc([N+](=O)[O-])cc2)cc1C</smiles>

15

scheme3 


$\begin{array}{ccc}\mathrm{OCN}-\left(\mathrm{CH}_{2}\right)_{3}-\mathrm{Cl} & \mathrm{OCN}-\left(\mathrm{CH}_{2}\right)_{2}-\mathrm{I} & \mathrm{OCN}-\left(\mathrm{CH}_{2}\right)_{2}-\mathrm{COOCH}_{3} \\ \mathbf{6} & \mathbf{8} & \mathbf{1 1}\end{array}$

figure 1 

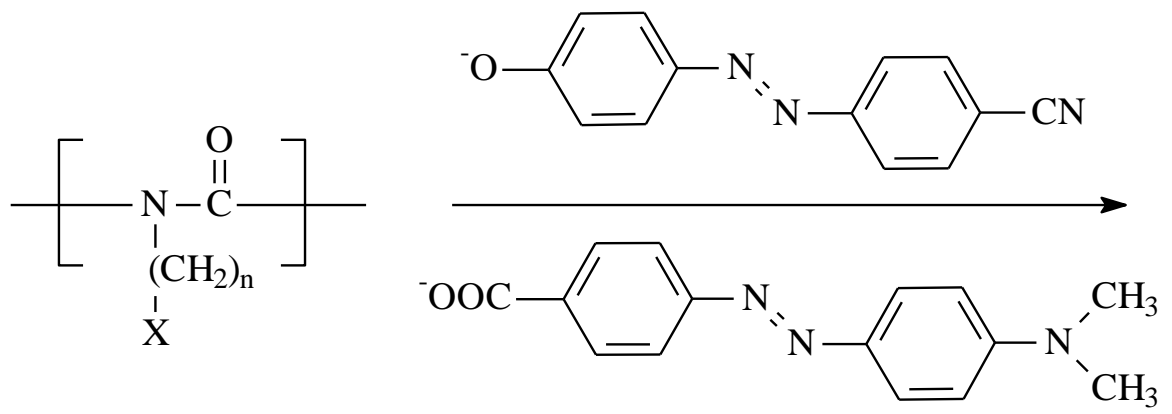

polymer degradation

figure 2 

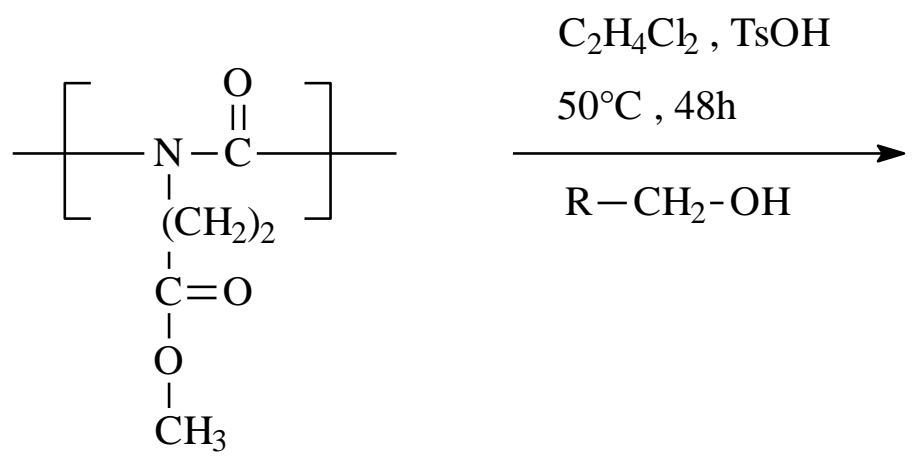

figure 3

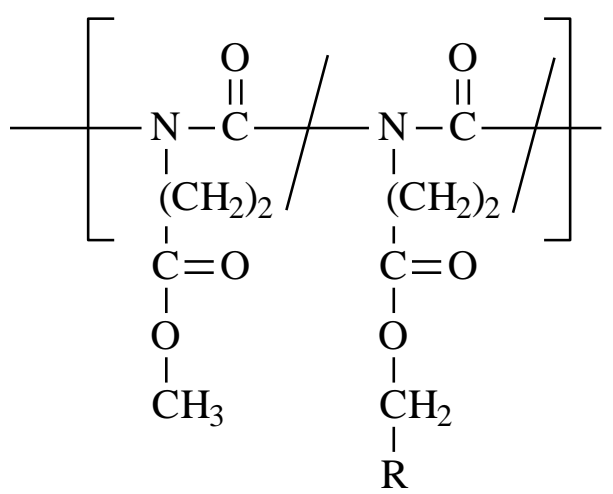


Table 1: Properties of polymers 1-5

\begin{tabular}{|c|c|c|c|c|c|c|c|c|c|c|}
\hline Polymer & $\begin{array}{c}x_{1}^{a} / \\
\%\end{array}$ & $x_{5}{ }^{a} /$ & $\begin{array}{c}x_{6}{ }^{a} / \\
\%\end{array}$ & $\begin{array}{c}x_{8}{ }^{a} / \\
\%\end{array}$ & $\begin{array}{c}x_{11}^{a} / \\
\%\end{array}$ & $\begin{array}{c}\text { Yield / } \\
\%\end{array}$ & $\begin{array}{c}\bar{M}_{n}^{\mathrm{b}} / \\
10^{3} \mathrm{~g} \cdot \mathrm{mol}^{-1}\end{array}$ & $D^{c}$ & $\begin{array}{c}T_{g}{ }^{d} / \\
{ }^{\circ} C\end{array}$ & $\begin{array}{c}{[\alpha]_{20}^{D} /} \\
\operatorname{deg}^{-1} \cdot d m^{-1} \cdot g^{-1} \cdot m l\end{array}$ \\
\hline Pol 1 & 80 & & 20 & & & 68 & 10,1 & 2,0 & $*$ & 0 \\
\hline Pol 2 & 64 & 6 & 30 & & & 73 & 9,2 & 2.1 & $*$ & $-465^{\mathrm{e}}$ \\
\hline Pol 3 & 50 & 10 & & 40 & & 22 & 4,2 & 1,9 & $*$ & $-498^{\mathrm{e}}$ \\
\hline Pol 4 & 0 & & & & 100 & 50 & 44,2 & 2,2 & 46 & 0 \\
\hline Pol 5 & 50 & & & & 50 & 40 & 36,3 & 2,1 & 42 & 0 \\
\hline
\end{tabular}

* not detected

${ }^{a}$ mol percentage of the isocyanate in the feed

${ }^{\mathrm{b}}$ measured by GPC in THF towards polystyrene standards

${ }^{c}$ polydispersity : $\overline{\mathrm{M}}_{\mathrm{w}} / \overline{\mathrm{M}}_{\mathrm{n}}$

${ }^{\mathrm{d}}$ measured by DSC

${ }^{\mathrm{e}} \mathrm{c}=5.0$ in $\mathrm{CHCl}_{3}$ 
Table 2: Properties of polymers $4 \boldsymbol{a}-\mathbf{5 b}$

\begin{tabular}{|c|c|c|c|c|c|c|c|}
\hline Polymer & Prepolymer & $\mathrm{R}-\mathrm{CH}_{2}-\mathrm{OH}$ & $\begin{array}{c}\boldsymbol{D F}^{\mathrm{a}} / \\
\%\end{array}$ & $\begin{array}{c}\bar{M}_{n}^{b} / \\
10^{3} \cdot g . m o l^{1}\end{array}$ & $D^{c}$ & $\begin{array}{c}T_{g}^{d} / \\
{ }^{o} \mathrm{C}\end{array}$ & $\begin{array}{c}{[\alpha]_{20}^{D} /} \\
10^{3} \mathrm{deg}^{-1} \cdot \mathrm{dm}^{-1} \cdot \mathrm{g}^{-1} \cdot \mathrm{ml}\end{array}$ \\
\hline Pol 4a & Pol 4 & 13 & 20 & 44.6 & 2.1 & 45 & 0 \\
\hline Pol 4b & Pol 4 & 15 & 30 & 45.2 & 2.3 & 48 & $-2.3^{e}$ \\
\hline Pol 5a & Pol 5 & 13 & 15 & 38.2 & 2.4 & 42 & 0 \\
\hline Pol 5b & Pol 5 & 15 & 15 & 34.1 & 2.3 & 45 & $-1.8^{\mathrm{f}}$ \\
\hline
\end{tabular}

${ }^{\mathrm{a}}$ degree of functionalisation, determined by ${ }^{1} \mathrm{H}-\mathrm{NMR}$ spectroscopy

${ }^{\mathrm{b}}$ measured by GPC in THF towards polystyrene standards

${ }^{\mathrm{c}}$ polydispersity : $\overline{\mathrm{M}}_{\mathrm{w}} / \overline{\mathrm{M}}_{\mathrm{n}}$

${ }^{\mathrm{d}}$ measured by DSC

${ }^{\mathrm{e}} \mathrm{c}=3 \cdot 4 \cdot 10^{-2}$ in $\mathrm{THF}$

${ }^{\mathrm{f}} \mathrm{c}=5 \cdot 2 \cdot 10^{-2}$ in $\mathrm{THF}$ 